\title{
Chagas Disease: A Neglected Disease
}

\author{
Mohemmed Faraz Khan ${ }^{1}$, Wasim Akhtar' ${ }^{1}$ Mohammad Shaquiquzzaman ${ }^{1}$, Garima Verma ${ }^{1}$, Sarwat Tauhid ${ }^{2}$, \\ Syed Rashiduddin ${ }^{2 *}$ and Mohammad Mumtaz Alam ${ }^{1 *}$ \\ ${ }^{1}$ Department of Pharmaceutical Chemistry, School of Pharmaceutical Education and Research, India \\ ${ }^{2}$ Department of Chemistry, Oriental College, India
}

Submission: July 03, 2017; Published: July 25, 2017

*Corresponding author: Syed Rashiduddin, Department of Chemistry, Oriental College, India; Email: aldol1234@gmail.com Mohammad Mumtaz Alam, Department of Pharmaceutical Chemistry, School of Pharmaceutical Education and Research, India; Email:drmmalam@gmail.com

\begin{abstract}
Chagas disease or American trypanosomiasis is a neglected disease caused by Trypanosoma cruzi and spread by insects 'triatomine' or 'kissing bugs'. Once, this disease was completely confined to the region of Latin America, but has now spread to different regions of the world due to immigration. Around 6 to 7 million people across the world are affected with this infection. This disease presents itself in two phases: acute and chronic, each with its own characteristic features. Various diagnostic techniques are available to confirm this infection. Benznidazole and nifurtimox are clinically used to relive the infected patients. Both these have $100 \%$ efficacy, if given soon after infection at the onset of acute phase. However, both of them are associated with some limitations, thereby necessitating the need for novel and safe agents.
\end{abstract}

Keywords: Chagas disease; Diagnosis; Treatment; Trypanosomiasis; Parasitemia

Abbreviations: T. cruzi: Trypanosoma cruzi; ELISA: Enzyme Linked Immunosorbent Assay

\section{Introduction}

Chagas disease, which is also known as American trypanosomiasis is an infection caused by the protozoan, Trypanosoma cruzi (T. cruzi). It is generally transmitted by feces of a triatomine insect, also known as kissing bugs belonging to family Reduviidae [1]. As per WHO report, 2017, about 6 to 7 million people are estimated to be infected with T. cruzi. This disease is not constrained to Latin America, where it is endemic in 21 countries. However, this is spreading to other areas like Europe, North America, Japan and Australia due to international immigration. It is a major contributor for deaths from parasitic disease [2]. This disease is considered as a proxy for poverty and disadvantage as it generally affects population group with low visibility and little political voice. It is generally neglected by researchers but is reported to have significant effect on morbidity and mortality [3]. Since, this disease affects majority people living in poverty in remote areas, less than $1 \%$ of the people have access to diagnosis and treatment [2].

Development of this disease can be due to different modes of transmission which can be vectorial, congenital, oral or latrogenic. Vectorial refers to the transmission by the vector 'kissing bug'. Congenital happens from mother to child. Oral mode of transmission is through the ingestion of contaminated food or drink. Latrogenic is due to contaminated blood transfusion or organ transplantation $[2,4,5]$.

Variable clinical presentation is observed in humans. Just following the parasite infection, there is a short acute phase in which there is abundant parasitemia which is relatively easy to detect by direct blood examination. Very mild or nonspecific symptoms make recognition of the contagion difficult. Majority of the patients of this phase go unrecognized due to scarcity or absence of the clinical manifestations. Following this acute phase, the disease enters chronic phase characterized by long, asymptomatic clinical latency that lasts for 10-30 years or throughout life. In this phase, around $30 \%$ of the infected people develop one of the clinical manifestations like cardiomyopathy and/or mega gastrointestinal syndromes [6]. Progressive heart failure and sudden deaths are the main causes of deaths in these patients [7].

\section{Life Cycle of T. cruzi}

This disease gets transmitted when an infected triatomine insect vector takes a blood meal and releases trypomastigotes 
in its feces near site of wound. These trypomastigotes enter the host through wound or intact mucosal membranes. Upon invasion of cells near the site of inoculation they get differentiated into intracellular amastigotes. Amastigotes multiply by binary fission and differentiate into trypomastigotes and then are released into circulation as bloodstream. These forms then infect cells from a variety of and get transformed into intracellular amastigotes in new infection sites. Clinical manifestations can result from this infective cycle. Kissing bugs become infected by feeding on human or animal blood that contains circulating parasites. These ingested trypomastigotes get transformed into epimastigotes in the vector's midgut. These parasites multiply and get differentiated into infective metacyclic trypomastigotes in the hindgut $[8,9]$. Life cycle of the parasite is shown in Figure 1.

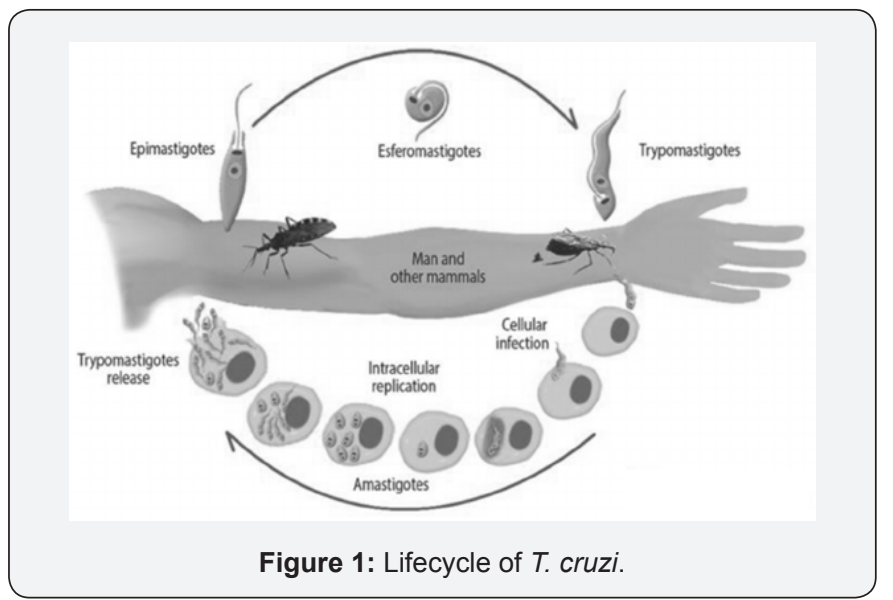

\section{Diagnosis and Treatment}

Diagnosis of this fatal disease can be done by both direct and indirect parasitological methods, molecular method. Direct parsitological methods for detection of acute phase include examination of fresh samples, blood smear, micro-strout test and strout concentration method. Xenodiagnosis and blood culture are a part of indirect methods. Polymerase chain reaction can also be employed for determination of acute phase of the disease [10]. Chronic phase can be detected by serological methods by enzyme linked immunsorbent assay (ELISA), indirect immunofluorescence, indirect haemagglutination and Western blot $[11,12]$.

Since 1960s, the only drugs available for the treatment of this infection have been benznidazole and nifurtimox (Figure 2) [13]. These two have been the mainstay of parasiticidal treatment for the past 50 years, despite the fact that their efficacy and safety profile is far from ideal conditions. Nifurtimox was the first drug used. This is administered orally in three to four doses for a period of 60-90 days. Anorexia, weight loss, neurological disorders, digestive malfunctions like nausea, vomiting and occasionally fever and rash are the frequent side effects associated with the use of nifurtimox [14,15].

Benznidazole is however preferred over the use of nifurtimox due to its better tolerability profile, tissue penetration and efficacy. It is administered orally in two or three doses usually for a period of 60 days. Common side effects of its use are hypersensitivity, digestive intolerance, headache and sleeping disorders. Neuropathy and depression of bone marrow are very rare $[16,17]$. Researchers are actively involved in the development of novel agents. However, the major obstacle associated is poor translation of in vivo data to human disease. Animal models available bear a drawback of limited predictive value [18-23].<smiles>C=S1(=O)CCN(/N=C/c2ccc([N+](=O)[O-])o2)C(C)C1</smiles>

Figure 2: Structure of Benzimidazole and Nifurtimox.

\section{Conclusion}

Chagas disease is one of the neglected tropical diseases. Benzidazole and nifurtimox have been the mainstay for treatment of this infection since long. However, there are many shortfalls associated with these drugs which necessitate the need for development of newer agents with better safety and efficacy profile.

\section{References}

1. de Oliveira AP, Ayo CM, Bestetti RB, Brandão de Mattos CC, et al. (2016) The role of CCR5 in Chagas disease-a systematic review. Infect Genet Evol 45: 132-137.

2. Chatelain E (2017) Chagas disease research and development: Is there light at the end of the tunnel? Comput Sruct Biotech J 15: 98-103.

3. WHO (2010) First WHO report on neglected tropical diseases: working to overcome the global impact of neglected tropical diseases. Geneva, Switzerland.

4. Dias JC, Neto AV, Luna EJ (2011) Alternative transmission mechanisms of Trypanosoma cruzi in Brazil and proposals for their prevention. Rev Soc Bras Med Trop 44(3): 375-379.

5. Howard EJ, Xiong X, Carlier Y, Sosa-Estani S, Buekens P (2013) Frequency of the congenital transmission of Trypanosoma cruzi: a systematic review and meta-analysis. BJOG 121(1): 22-33.

6. Sanchez-Guillen MDC, Lopez-Colombo A, Ordonez-Toquero, GomezAlbino, Ramos-Jimenez, et al. (2006) Clinical forms of Trypanosoma cruzi infected individuals in the chronic phase of Chagas disease in Puebla, Mexico. Mem Inst Oswaldo Cruz 101(7): 733-739.

7. Ayub-Ferreira SM, Mangini S, Issa VS, Cruz FD, Bacal F, et al. (2013) Mode of death on Chagas heart disease: comparison with other etiologies. A subanaysis of the REMADHE prospective trial. PLoS Negl Trop Dis 7(4): e2176.

8. Tyler KM, Engman DM (2001) The life cycle of Trypanosoma cruzi revisited. Int J Parasit 31(5-6): 472-481.

9. Carrea A, Diambra L (2017) Commentary: systems biology approach to model the life cycle of Trypanosoma cruzi. Front Cell Infect Microbiol.

10. Alvarez-Hernandez DA, Franyuti-Kelly GA, Diaz-Lopez-Silva R, Gonzalez-Chavez AM, Gonzalez-Hermosillo-Cornejo D, et al. (2016) Chagas disease: current perspectives on a forgotten disease. Rev Med del Hospital Gen de Mexico. 
11. B WA, G IH, L MI, M LJ, V PM, et al. (2008) Part VI: Antiparasitic treatment for Chagas disease. Rev Chilena Infectol 25(5): 384-389.

12. Antinori S, Galimberti L, Bianco R, Grande R, Galli M, et al. (2017) Chagas disease in Europe: a review for the internist in the globalized world. Eur J Int Med S0953-6205(17): 30177-30182.

13. Murcia L, Carrilero B, Saura D, Iborra MA, Seqovia M (2013) Diagnosis and treatment of Chagas disease. Enferm Infecc Microbiol Clin 31(1): 26-34.

14. Pozas R, Carballo J, Castro C, Rubio J (2005) Synthesis and in-vitro antitrypanosomal activity of novel Nifurtimox analogues. Bioorg Med Chem Lett 15(5): 1417-1421.

15. Boiani M, Piacenza l, Hernandez P, Boiani L, Cerecetto H, et al. (2010) Mode of action of Nifurtimox and $\mathrm{N}$-oxide-containing heterocycles against Trypanosoma cruzi: Is oxidative stress involved? Biochem Pharmacol 79(12): 1736-1745.

16. Vallejo A, Monge-Maillo B, Gutiérrez C, Norman FF, López-Vélez $\mathrm{R}$, et al. (2016) Changes in the immune response after treatment with benznidazole versus no treatment in patients with chronic indeterminate Chagas disease. Acta Trop 164: 117-124.
17. Andrade P, Galo OA, Carvalho MR, Lopes CD, Carneiro ZA, et al. (2015) 1,2,3-Triazole-based analogue of benznidazole displays remarkable activity against Trypanosoma cruzi. Bioorg Med Chem 23(21): 68156826.

18. Monge-Maillo B, Lopez-Velez R (2017) Challenges in the management of Chagas disease in latin American migrants in Europe. Cli Microb Infect 23(5): 290-295.

19. Perez-Molina JA, Molina I (2017) Chagas disease. Lancet 278: 7211.

20. Bermudez J, Davies C, Simonazzi A, Real JP, Palma S (2015) Current drug therapy and pharmaceutical challenges for Chagas disease. Acta Trop 156: 1-16.

21. Conners EE, Vinetz JM, Weeks JR, Brouwer KC (2016) A global systematic review of Chagas disease prevalence among migrants. Acta Trop 156: 68-78.

22. Perez CJ, Lymbery AJ, Thompson RCA (2014) Chagas disease: the challenge of polyparasitism? Trends Parasit 30(4): 176-182.

23. Justi SA, Galvao C (2017) The evolutionary origin of diversity in Chagas disease vectors. Trends Parasit 33(1): 42-52.

\section{Your next submission with Juniper Publishers will reach you the below assets}

- Quality Editorial service

- Swift Peer Review

- Reprints availability

- E-prints Service

- Manuscript Podcast for convenient understanding

- Global attainment for your research

- Manuscript accessibility in different formats

( Pdf, E-pub, Full Text, Audio)

- Unceasing customer service

Track the below URL for one-step submission https://juniperpublishers.com/online-submission.php 